\title{
Determination of Milling Module for Different Categories of Concentrates Feeds (Grain: Wheat and Corn)
}

\author{
Victor A. BĂRBIERU*, Mircea MUNTEAN, Adriana DAVID, Ovidiu MARIAN \\ University of Agricultural Sciences and Veterinary Medicine, 3-5 Manastur Street, 400372 Cluj-Napoca, \\ Romania \\ *Corresponding author, email: barbieru@iname.com
}

Bulletin UASVM Animal Science and Biotechnologies 71(2) / 2014,

Print ISSN 1843-5262; Electronic ISSN 1843-536X

DOI:10.15835/buasvmcn-asb:10401

\begin{abstract}
The study was made in order to establishing qualitative indexes of concentrate feeds made by hummer mill MB-7,5 equipped with 3 type of sieves and 2 type of hummers on mill rotor. Granularity tests were made by Sieving Machine AS-300 with 4 sieve-plates. Concentrate feeds were wheat and corn at 2 different humidity levels, from each milling product were tacked 3 samples for Sieving Machine, were made averages to estimate milling module. Results show us the major influence of grain type (wheat or corn) in granularity determination, humidity of grain modify also our expected results.
\end{abstract}

Keywords: grain, granularity indexes, milling, sieving

\section{INTRODUCTION}

Intensive animal breeding in relative restricted spaces is conditioned by well-balanced feeds in all nutrients, which provide a good productive capacity and health maintenance. Using cereals and other vegetal feeds is carried out after processing operations (Stănilă, 2013), (sorting, milling) to ensure their consumption and the possibility of mixing with other components, to achieve the combined feeds. Determination of milling module for analyzed feeds (wheat and corn) is framing on different animal species for samples obtained by mill using 3 different sieves. Sieving operation is also important to separate milling product in 4 different categories (according to sieves holes) to see the amount of small fractions and big fractions as well. Energy consumption per product unit is also an indicator of the approach waiting for him ahead.

\section{MATERIAL AND METHODS}

Raw Materials were grains -wheat and cornat two-humidity level (11\% and 18\%).
The equipments used were: For milling (grinding) we used Feed processing outfit "Bonțida type" (Fig. 1) which content: 1 hammer mill (MB7.5 with 0.7 tons/hour maximum productivity and $7.5 \mathrm{~kW}$ electric engine power), 1 horizontal mixer (Himmel type), 3 grains tanks, 2 recipients for milling products, mechanical transporters, electronic scales for weigh under the mixer support, computer for commands and recipes. Hammer mill (Fig. 2) was equipped for our experiments with 2 different types of hammers on mill rotor and 3 different types of sieve (the size of holes are $3 \mathrm{~mm}, 6 \mathrm{~mm}$ and $8 \mathrm{~mm}$ ).

For sieving (sifting) we used Sieving Machine AS 300 (Fig. 3) equipped with 4 sieves (plates) and collector, the mash (holes) size of sieves are $0.50 \mathrm{~mm}$ (s1), $0.63 \mathrm{~mm}$ (s2), $1.25 \mathrm{~mm}$ (s3) 2.50 $\mathrm{mm}$ (s4). AS $\mathbf{3 0 0}$ was set with $2.0 \mathrm{~mm} / \mathrm{g}$ amplitude of vibration for 60 seconds and samples have 500 gram weigh.

In order to estimate the granularity of these milling products we use following equations (Sârb and Goia, 1995): 


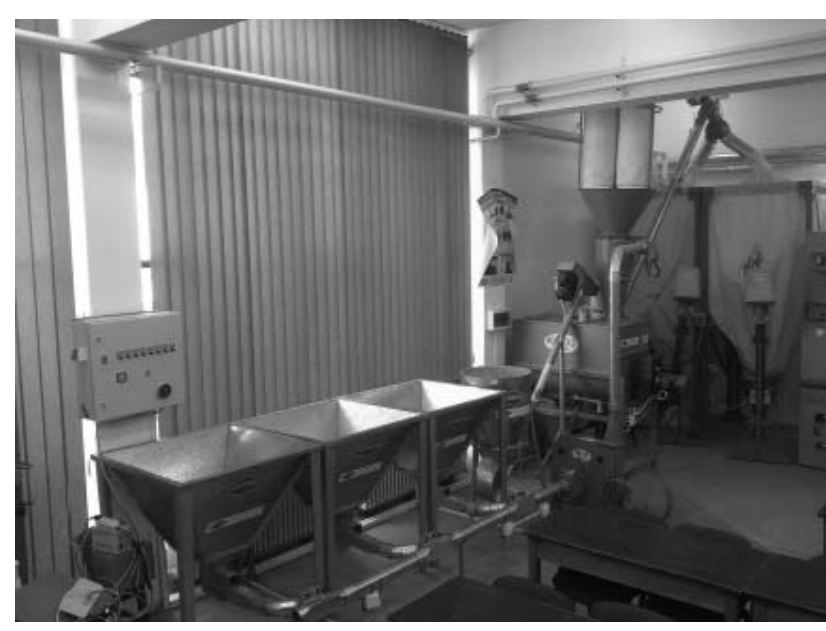

Fig. 1. Feed processing unit "Bontida Type

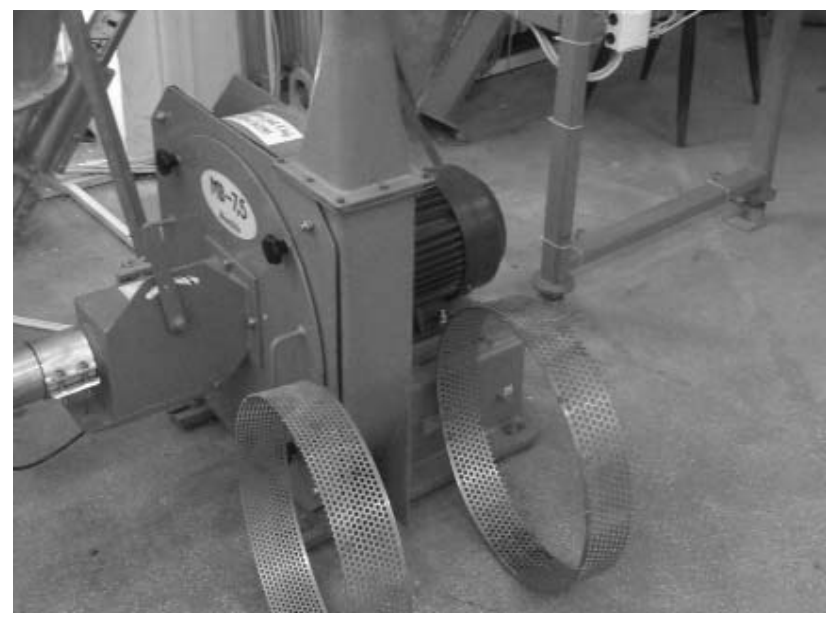

Fig. 2. Hammer Mill MB-7,5

$$
M=\left[p_{0} G_{0}+p_{1} G_{1}+p_{2} G_{2}+p_{3}\left(G_{3}+G_{4}\right)\right] / N
$$

where: M-milling module; $\mathrm{G}_{0}$-quantity of product on collector; $G_{1}$-quantity of product on sieve 1 $(0.50 \mathrm{~mm}) ; \mathrm{G}_{2}$-quantity of product on sieve $2(0.63$

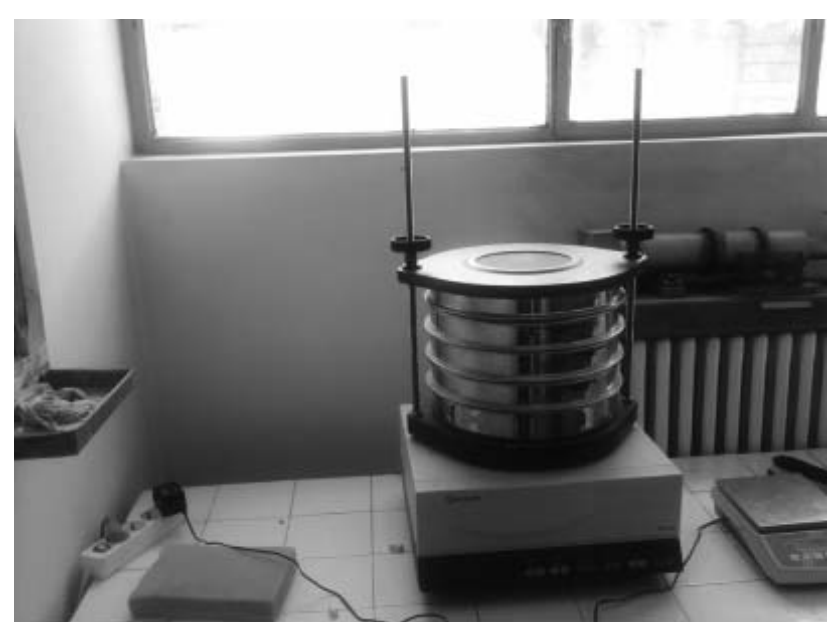

Fig. 3. Sieving Machine AS-300

$\mathrm{mm}) ; \mathrm{G}_{3}$-quantity of product on sieve $3(1.25 \mathrm{~mm})$; $\mathrm{G}_{4}$-quantity of product on sieve $4(2.50 \mathrm{~mm}) \cdot \mathrm{p}_{0}$, $p_{1}, p_{2}, p_{3}, p_{4}$ - are estimate as average between two sieves neighbors, (for AS-300 $\mathrm{p}_{0}=0.25, \mathrm{p}_{1}=0.56$, $\left.\mathrm{p}_{2}=0.94, \mathrm{p}_{3}=1.87\right) ; \mathrm{N}$-total weight of the sample (g)

If the value of $<M>$ is less than 1 the milling is thin class, between 1 and 1.8 is medium class, and between 1.8 and 2.6 is big class (Şara and Benţea, 2011).

\section{RESULTS AND DISCUSSION}

During grains milling were taken 3 samples from each determination for Sieving Machine AS300 . We made the averages for results of sieving, which are presented in 2 tables for wheat and corn as well. For a better view of milling module increasing or decreasing values according to mill

Tab. 1. Average value of wheat sieving and milling module

\begin{tabular}{|c|c|c|c|c|c|c|c|c|c|}
\hline \multirow{2}{*}{$\begin{array}{l}\text { Hammer } \\
\text { type }\end{array}$} & \multirow[t]{2}{*}{ Humidity } & \multirow{2}{*}{$\begin{array}{c}\text { Sieve } \\
\text { of } \\
\text { mill }\end{array}$} & \multicolumn{5}{|c|}{ Sieves of AS-300 } & \multirow{2}{*}{$\begin{array}{l}\text { Total } \\
<\mathrm{N}> \\
\text { (g) }\end{array}$} & \multirow{2}{*}{$\begin{array}{c}\text { Milling } \\
\text { Module } \\
<\mathrm{M}>\end{array}$} \\
\hline & & & $\begin{array}{l}\text { Collector } \\
<G_{0}>\text {, (g) }\end{array}$ & $\begin{array}{c}\text { Sieve } 1 \\
<G_{1}> \\
(\mathrm{g})\end{array}$ & $\begin{array}{c}\text { Sieve } 2 \\
<G_{2}> \\
(\mathrm{g})\end{array}$ & $\begin{array}{c}\text { Sieve } 3 \\
<G_{3}> \\
(\mathrm{g})\end{array}$ & $\begin{array}{c}\text { Sieve } 4 \\
<G_{4}> \\
(\mathrm{g})\end{array}$ & & \\
\hline \multirow{6}{*}{ I } & \multirow{3}{*}{ I } & 1 & 164 & 13 & 131 & 176 & 12 & 496 & 1.05 \\
\hline & & 2 & 112 & 16 & 145 & 211 & 14 & 496 & 1.19 \\
\hline & & 3 & 98 & 10 & 105 & 263 & 21 & 497 & 1.32 \\
\hline & \multirow{3}{*}{ II } & 1 & 110 & 13 & 127 & 234 & 12 & 496 & 1.23 \\
\hline & & 2 & 108 & 10 & 114 & 247 & 19 & 498 & 1.27 \\
\hline & & 3 & 73 & 5 & 82 & 285 & 52 & 497 & 1.46 \\
\hline \multirow{6}{*}{ II } & \multirow{3}{*}{ I } & 1 & 160 & 17 & 182 & 135 & 2 & 494 & 0.96 \\
\hline & & 2 & 104 & 10 & 124 & 246 & 13 & 497 & 1.27 \\
\hline & & 3 & 102 & 12 & 125 & 240 & 18 & 497 & 1.27 \\
\hline & \multirow{3}{*}{ II } & 1 & 150 & 13 & 157 & 164 & 12 & 496 & 1.05 \\
\hline & & 2 & 124 & 11 & 126 & 220 & 16 & 497 & 1.20 \\
\hline & & 3 & 72 & 3 & 78 & 292 & 52 & 497 & 1.48 \\
\hline
\end{tabular}




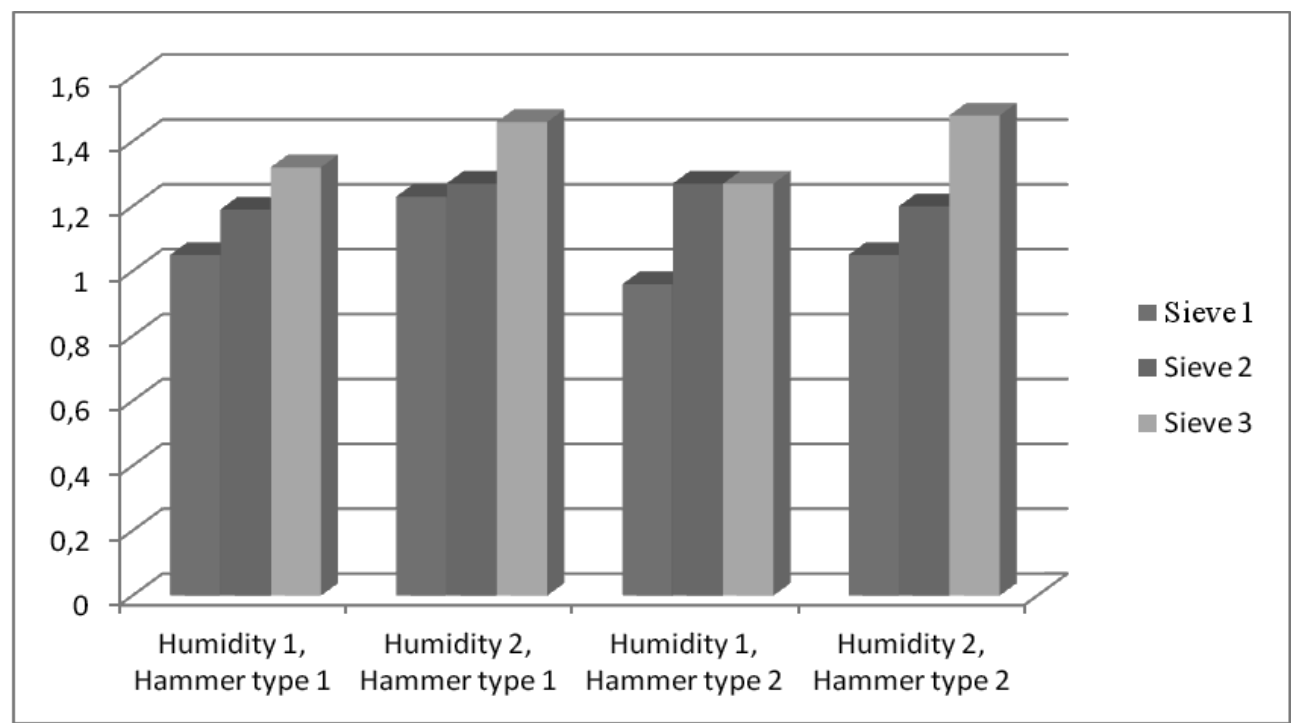

Fig. 4. Milling module $<\mathrm{M}>$ values for wheat, according to mill sieves holes, level of humidity and hammer type

Tab. 2. Average value of corn sieving and milling module

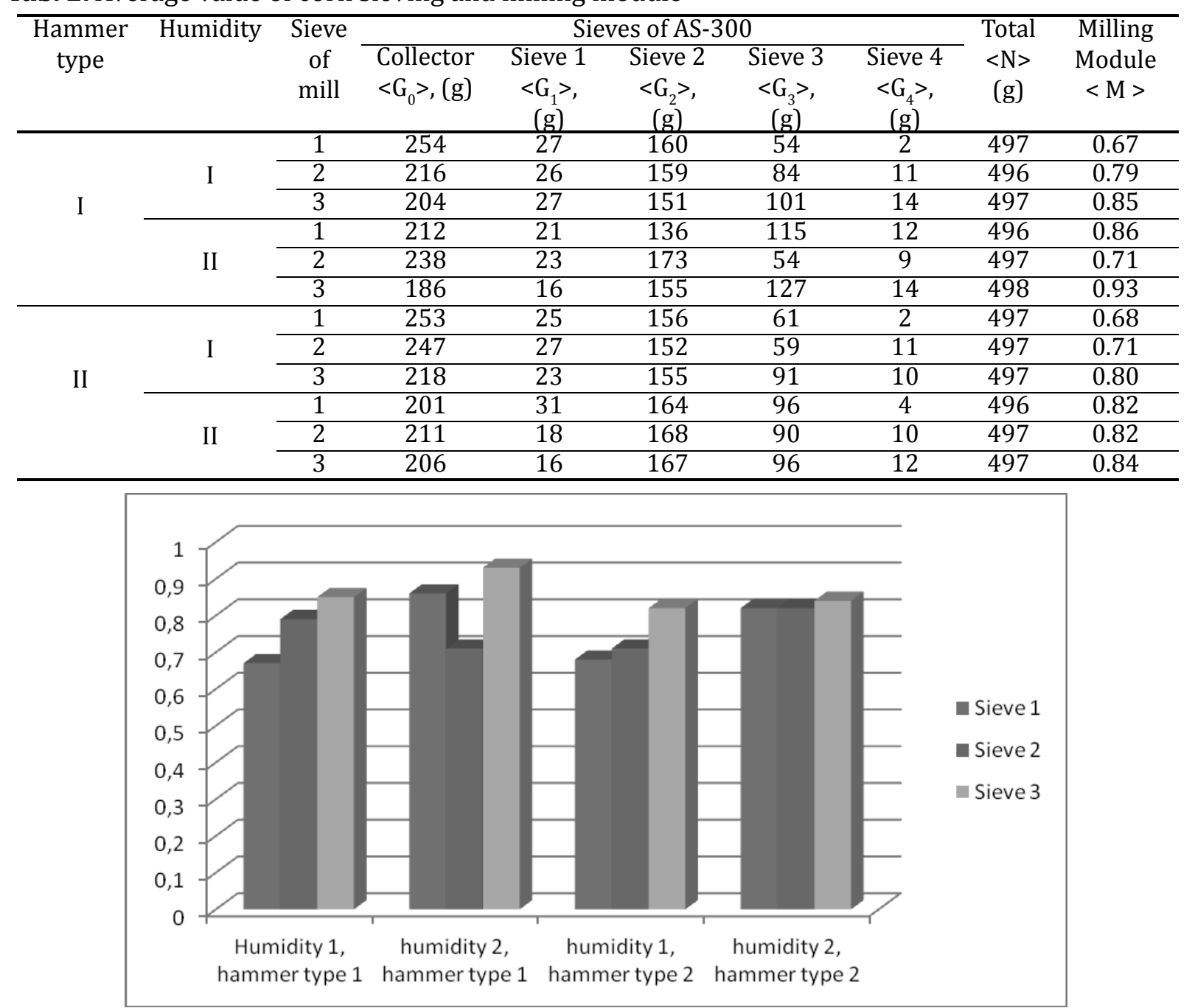

Fig. 5. Milling module $<\mathrm{M}>$ values for corn, according to mill sieves holes, level of humidity and hammer type 
sieve used, we made 2 graphic representations as well.

According to estimation of milling module $<$ M $>$ from Table 1 the products are in medium granularity class and the increasing of values (Fig. 4) are depending by size of the holes from mill sieves, level of humidity and hammer type.

Results of milling module for corn are less than 1 in all cases, so granularity is in thin class, humidity of corn have influence in case of hammer type 1 where at second sieve the value of $\langle$ M $>$ is decreasing and in case of hammer type 2 at humidity level 2 the values of $<\mathrm{M}>$ are almost the same (Fig. 5)

\section{CONCLUSION}

The most important factor for framing milling module is type of grains (cereals), for our experiments the results obtained show for wheat a medium granularity the values of $<M>$ were between 0.96-1.48 and for corn we obtain thin class of granularity the values of $<\mathrm{M}>$ were less than 1 in all cases (0.67-0.93).

Second factor which have a influence for milling granularity was humidity of raw materials (cereals) especially in corn case where for level 2 of humidity (18\%) for hammer type 1 the values of $<\mathrm{M}>$ decrease to sieve 2 and for hammer type 2 remain to same level.

Increasing of granularity expected when the mill sieves are replaced (3-6-8 $\mathrm{mm}$ holes) was only for low humidity level (11\%), hammer type from mill rotor haven't a major influence.

\section{REFERENCES}

1. Şara A, M Bențea (2011). Alimentaţia animalelor. Ed. Risoprint, Cluj- Napoca, 277.

2. Sârb V, V Goia (1995). Maşini şi instalaţii pentru zootehnie. Ed. Genesis, Cluj-Napoca, 322.

3. Stănilă Sorin (2013). Utilaje în industria alimentară. Ed. Risoprint, Cluj-Napoca, 533. 